\title{
POST-HURRICANE DAMAGE ASSESSMENT ON GREENHOUSE FIELDS WITH USE OF SAR DATA
}

\author{
N. Demir ${ }^{1, *}$, Y.E. Eryilmaz ${ }^{2}$, S. Oy ${ }^{1}$ \\ ${ }^{1}$ Akdeniz University, Space Science, and Technologies, 07058 Konyaaltı Antalya, Turkey - nusretdemir@akdeniz.edu.tr, \\ selenoy171@gmail.com \\ 2 Akdeniz University, Remote Sensing and Geographic Information Systems, 07058 Konyaaltı Antalya, Turkey - \\ yunusemre1534@gmail.com
}

Commission VI, WG VI/4

KEY WORDS: SAR, Tornadoes, Disaster Management, Greenhouses, Remote Sensing, SENTINNEL

\begin{abstract}
:
Hurricanes occur without any control of human-being, and it causes large scale loss of life and properties. They happen in the very short timeline and cannot be stopped by the people after it starts to occur. Therefore, the damage has to be assessed just after the disaster for an effective management. Radar images have advantages since the radar sensor can operate in all weather conditions, not be affected by the clouds, therefore use of SAR imagery is useful to identify the damage and loss of properties. In our study, AntalyaKumluca region has been selected, because a hurricane has occurred on 13th November 2017 and caused large damages especially in agricultural fields where there are lots of greenhouses. Two Sentinel 1A (S1A) images have been used, one from the pre-disaster period and the other is from the post-disaster period. Backscatter values are analyzed in both images. It is expected that the difference between $\mathrm{dB}$ values are expected to be larger than the $\mathrm{dB}$ value of the pre-disaster period, in case a large-scale damage happened. The fields which were affected by the disaster were found and compared with the Sentinel 2A (S2A) multispectral images to validate the occurred loss. The results show a high match between the detected damages in SAR image and the identical effected fields on multispectral image from the post-disaster period.
\end{abstract}

\section{INTRODUCTION}

Over the past decade, disaster Management has become a popular topic with the development of remote sensing techniques, Hurricanes are known as the most violent storms on Earth and have major hazards in both rural and urban areas. These can cause widespread destruction and to loss of life. Therefore, it is important to determine the damage after the disaster.

Most studies from past to date have been based on passive optical remote sensing data (Ayala-Silva and Twumasi, 2004; Aosier et al., 2007; Wang et al., Chehata et al., 2014). Fewer studies have focused on detection of hurricane damage using Radar data. SAR data has many advantages when compared to optical satellite data. The radar signal is active, and images could be taken at any time of day considering these signals are able to pass through the clouds. In addition, the SAR sensor allows for a continuous data acquisition, regardless weather conditions. These are especially significant for monitoring and management of disaster events.

In the literature, disaster management and post-disaster assessment studies that use SAR data examined, it is remarkable that there are more research works on two topics: forest damage detection and flood detection (Richards et al., 1987; Fransson et al., 2002; Ermert et al., 2012; Eriksson et al., 2012; Gokaraju and Turlapaty, 2015).

In this study, a method is proposed using S1A data and S2A satellite data for near real time damage assessment after a tornado disaster event.

\section{MATERIALS AND METHOD}

\subsection{Study Area}

In this study, Kumluca region of Antalya province that is located in Turkey is selected as test area (Figure 1). The city has a typical Mediterranean climate which has rainy winters and dry summers. At the study area, the average temperature ranges between $28.5^{\circ} \mathrm{C}$ and $9.6^{\circ} \mathrm{C}$ and the average annual precipitation is $1087.8 \mathrm{~mm}$ (MGM, 2018). In the city, the main source of income is agriculture, livestock farming, and tourism. Antalya is one of the main greenhouse produce regions of the country and when Kumluca is examined in terms of agricultural activities, it has a massive percentage in the amount of city's greenhouse cultivation (Emekli et al., 2008).

On 13th November 2017, a hurricane occurred and effected Finike, Kumluca and Demre regions of Antalya, it caused largescale damage. Mainly agricultural fields, buildings, and the greenhouses were damaged as consequence of this damage. The hurricane came out from the shoreline of Mavikent district in the Kumluca and touched down in this area produced a 1 kilometres long path of destruction which was up to 400 meters wide (Hurriyet Gazetesi, 2017; Sozcu Gazetesi, 2017).

\footnotetext{
* Corresponding author
} 

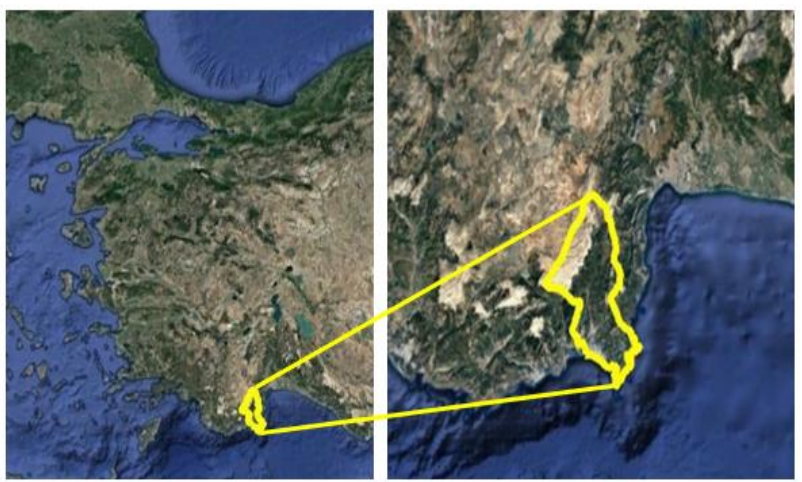

Figure 1. Study area, Antalya-Kumluca, Turkey (GoogleEarth)

\subsection{Used Data}



Figure 2. Original SENTINEL-1A images: a) pre-hurricane b) post-hurricane

Sentinel-1A was launched on April 3, 2014. It was fully operational and provided data on a regular basis. The data could acquire in every twelve days from Sentinel-1A. With both Sentinel-1A and Sentinel-1B operating, the repeat cycle is six days (ESA, 2013). The orbital swath width is $250 \mathrm{~km}$. For this study, Sentinel-1A dated on November 10, 2017, and November 22, 2017, images were used as basic data to determine fields which were affected by the tornado. These images were demonstrated in Figure 2. The SAR data were obtained in Interferometric Wide Swath Mode (IW) and GRD file format. Information about used SAR images is provided in Table 1.

\begin{tabular}{|l|l|}
\hline Date: & $\begin{array}{l}10.11 .2017 \text { (pre-disaster) } \\
22.11 .2017 \text { (post-disaster) }\end{array}$ \\
\hline Instrument: & SAR-C \\
\hline Polarisation: & VH \\
\hline Resolution (rgxaz): & $20 \times 22 \mathrm{~m}$. \\
\hline Pixel Spacing (rgxaz): & $10 \times 10 \mathrm{~m}$. \\
\hline
\end{tabular}
Table 1. Features of Sentinel-1A (ESA, 2013)


Figure 3. True colour composite of Sentinel-2 imagery
Sentinel-2A was launched on June 23, 2015. Afterward, Sentinel-2B was launched on March 7, 2017. Sentinel-2 satellite has 13 spectral bands and these bands are range from visible to SWIR. These bands hashigh-resolution: four bands at $10 \mathrm{~m}$, six bands at $20 \mathrm{~m}$ and three bands at $60 \mathrm{~m}$ spatial resolution (ESA, 2015). The technical specifications of the SENTINEL-2 satellite are given in Table 2. In the study, used images are given in Figure 3 and these images are used for comparison with the results from SAR image.

\begin{tabular}{|c|c|}
\hline Date: & $\begin{array}{l}08.11 .2017 \text { (pre) } \\
16.11 .2017 \text { (post) }\end{array}$ \\
\hline Spatial Resolution: & $10 \mathrm{~m}$. \\
\hline \multirow{4}{*}{$\begin{array}{l}\text { Spectral Bands } \text { (Central } \\
\text { wavelength-nm): }\end{array}$} & Band 2: $490 \mathrm{~nm}$ (Blue) \\
\hline & Band 3: $560 \mathrm{~nm}$ (Green) \\
\hline & Band 4: $665 \mathrm{~nm}(\mathrm{Red})$ \\
\hline & Band 8: $842 \mathrm{~nm}$ (NIR) \\
\hline Radiometric Resolution: & 12 bit \\
\hline Revisit Time: & 5 days \\
\hline Swath Width: & $290 \mathrm{~km}$ \\
\hline
\end{tabular}

Table 2. Technical specifications of SENTINNEL-2 satellite (ESA, 2015)

\subsection{Method}

There are basically four main steps in this study, which are (1) Pre-processing of Sentinel-1A,

(2) Detection of damaged area from Sentinel-1A,

(3) Processing of SENTINEL-2 as well as detection of damaged area from SENTINEL-2, and

(4) Change detection.

The first step in the algorithm was pre-processing of Sentinel-1 data. The process shall be divided into four groups and corrections were made with using Sentinel Application Platform Toolbox (SNAP 6.0):

- Subset of data

- Apply orbit file

- Radiometric calibration,

- Speckle filtering and

- Terrain corrections.

The corrected data was used to determine the damaged area by analysing backscatter values. Then, in pre-processing step, Sentinel-2 data were resampled and re-projected. The process Sentinel-2 data were classified using the K-mean that unsupervised classification algorithm. Finally, change detection was implemented by results of damage detection obtained from Sentinel-1A and Sentinel-2.

During pre-processing of Sentinel-1A, the SAR data were subset and then these data were applied into orbit-file. As consequence, the radiometric correction was required to apply to SAR images, hence radar backscatter of the reflecting surface could be fully represented by pixel values of the SAR images. (Veci, 2015). The data were calibrated for producing sigma bands. Speckle is a granular noise that is in original SAR images and dominating factor in radar imagery. The SAR images contain speckle that is a signal dependent salt-pepper noise. These speckles resulted in a SAR image that failed to have a constant mean radiometric level in homogeneous areas (Bruniquel and Lopes, 1997). The speckle noise does not reduce the image quality; however, it makes more difficult the interpretation (Čotar et al., 2016) Therefore, this step should be done before starting to analyse the radar images. The working principle of the Lee-Sigma filter requires speckle reduction for 
scattered scatters, averaging the pixels in a homogeneous field (Lee, 1983). This filter is developed by Lee in 1980 and has become a way to select homogeneous areas. Lee sigma filter is preferred to use due to its simplicity, its computational efficiency, and its effectiveness in speckle reduction. In this study, the SAR data were filtered to reduce salt-and-pepper noise using the Lee-Sigma filter of with a window size of $5 \times 5$ pixels. The last pre-processing step was terrain correction. Data that is obtained from SAR have many image distortions. The aim of terrain correction was compensated for these distortions. The data were geometrically corrected by using a digital elevation model (ASTER based DEM) in the resolution of 30 meters. The processed S1A data were given in Figure 3.
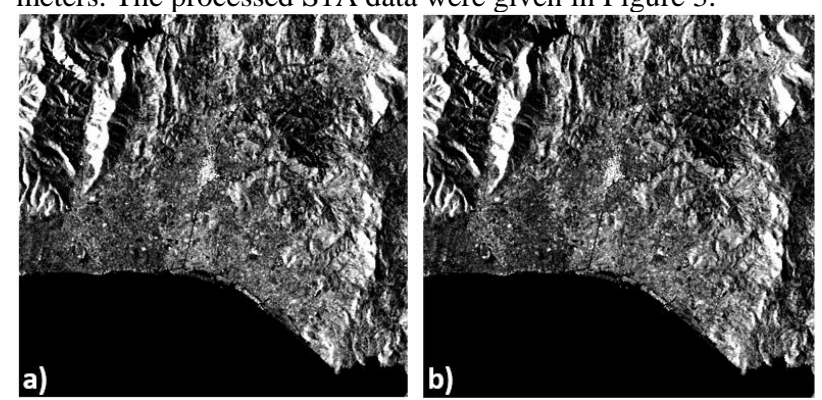

Figure 3. Pre-processed S1A data: a) pre-hurricane b) posthurricane

The SAR image pixels included generally radar backscattering intensity, the phase of the backscattered signal, and range information from the sensor to the target. Radar backscattering signals were influenced by many factors while they are backscattered from reached location, and the most important of these were land factors such as dielectric constant, surface roughness and terrain slope. Additionally, the dielectric constant is included moisture content (Chung et al., 2015). The open water areas acted as specular reflectors, produced black areas in the SAR image, due to low backscattering. A stronger echo was produced in areas such as buildings and urban areas as well as the echo from these areas are brighter. The SAR signals showed different reflection properties in moist and dry regions. Moist soils had lower reflection behaviour than dry soils. Therefore, a damaged area after a hurricane reflects will lower backscattering values due to moisture. Using differences of backscattering in the Sentinel 1 images, changes might be detected in surface conditions in pre- and post- hurricane sessions. In the computed difference image, positive values demonstrated a decrease in backscatter values and negative values were increased (Ermett et al., 2012). For this purpose, images of pre- and post-hurricane images were computed a difference image using VH band. The main steps of the change detection method are:

Step 1. Choose a polarisation and convert from linear to dB.

Step 2. Generate the difference image by computing the difference between $T_{1}$ (pre-hurricane) and $T_{2}$ (post-hurricane) images.

Step 3. Produce the change detection result by thresholding the difference image.

In this study, the proposed method used SAR images on the same geographical area at two different times (pre- and posthurricane) and it provided automatic change detection by computing the backscatter differences between the images. The method is defined as in Equation 1:

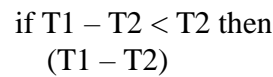

$\mathrm{T} 1$ is the backscatter value from the pre-hurricane image, and $\mathrm{T} 2$ is from the post-hurricane image.

\section{RESULTS}

The difference image was subtracted T2 from T1. According to Dobson and Ulaby (1986), a change in the radar back reflection of soil nod is caused by $11 \mathrm{~dB}$. At this stage, the threshold value was selected as 11 according to this information. The obtained difference image was shown in Figure 4.


Figure 4 . The detected potential damages from the difference image

Secondly, the detected damages were identified with Equation (1) and the results were shown in Figure 5.
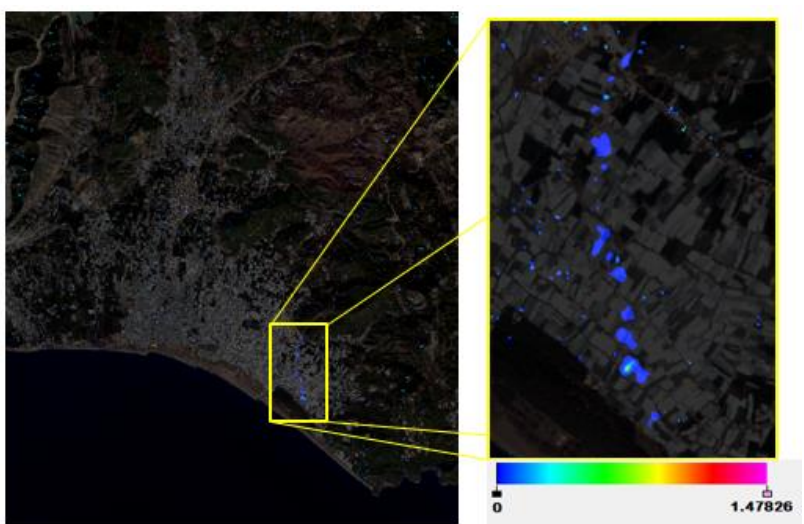

Figure 5 . The found potential damage by the proposed method

For evaluation of the results, the multispectral image was used. Sentinel 2A image was selected and pre and post-disaster images were classified with use of K-means clustering method. The difference between the classification results gave the areas where the hurricane effect. Then, the results from SAR were compared.

Sentinel-2 data were resampled using spatial resolution in blue band (B2) and using resampling method of SNAP software. Three different resampling methods were provided for the users by SNAP software. Resampling process was performed using Nearest Neighbour Interpolation that was very simple and quick. When the process is completed, a resampled image with $10 \mathrm{~m}$ spatial resolution was produced. Each band of the Sentinel-2 data was acquired as geometrically corrected and World Geodetic System (WGS84, Zone 36). Afterwards, the image might be cropped, and the study area is extracted. 
The classification of SENTINEL-2 images was performed using the K-means classifier (MacQueen, 1967). The classification results were as given in Figure 6 and Figure 7.
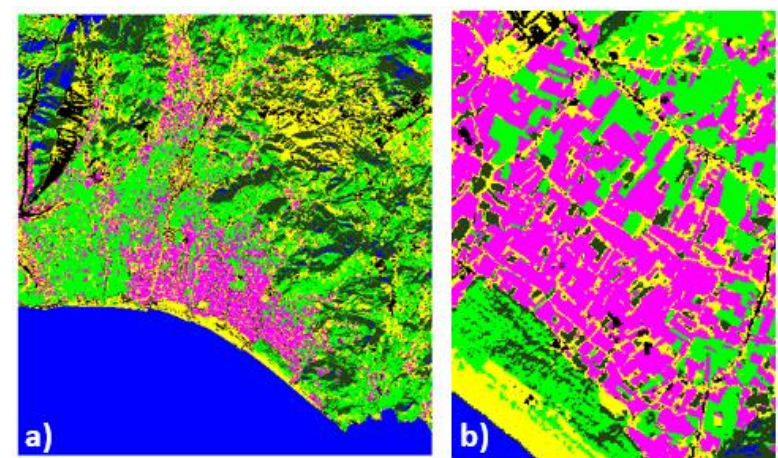

Figure 6. The classified image of pre-hurricane: a) Study area b) Hurricane-affected area (pink: greenhouse, yellow: free field, green: vegetable1, dark green: vegetable2, blue: water, black: shadow)


Figure 7. The classified image of post-hurricane: a) Study area b) Hurricane-affected area (pink: greenhouse, yellow: free field, green: vegetable1, dark green: vegetable2, blue: water, black: shadow)

The classified images were converted to grey scale image and the images were analysed to identify areas of change. The obtained raster data was converted to vector data format and the areas of the polygons were determined. Then, the damaged area was detected by thresholding the data. The damaged areas obtained from Sentinel-2 and Sentinel-1A were shown in Figure 8. Figure $8 \mathrm{a}$ showing the results of Sentinel-2 with the difference image. The red polygons represented the damage areas that obtained from the Sentinel-2 image, while the green ones showed the results that obtained from the difference image. As shown in the figure, the obtained polygons by two different methods overlapped in damages area, but the green polygons were identified more than blue. These polygons show the change of backscattering in those areas. Damage range of these areas might not be higher than the area which is requested to obtain. Additionally, this damage might be caused by humidity following the hurricane or wind. The other image (Figure $8 \mathrm{~b}$ ) shows the damage areas identified using Equation (1) with SENTINEL-2. This result covers less area than the difference image. Compared to the damaged area, the results were found in areas where severe destruction was been.
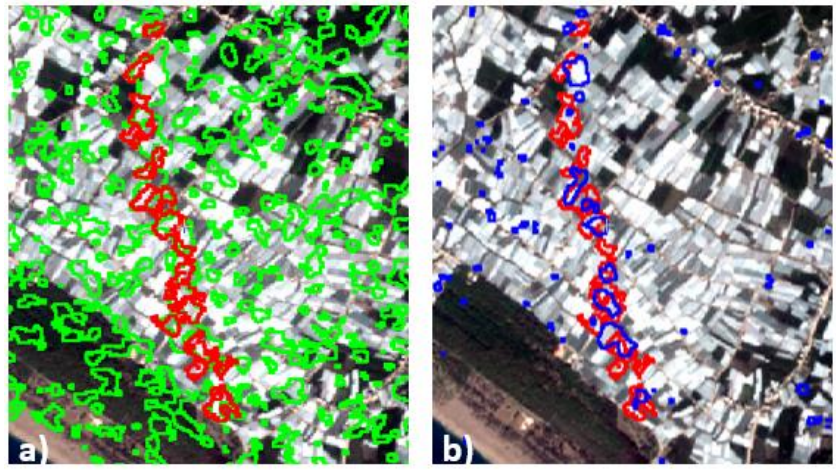

Figure 8. Comparison of damaged areas: a) S2A and the difference image b) S2A and detected result with an Equation (1) (red: S2A, green: difference image, blue: detection result with an Equation (1))

The change data identified by S2 was limited and closed. Thus, the polygon grids that located in the different grids were associated with each other, as shown in Figure 9 left image. Processed S2A pre-hurricane image overlaid with results were shown in the right image. The image on the left shows us the described results of using the first method. When Figure 9 was examined, the results showed a large overlap.
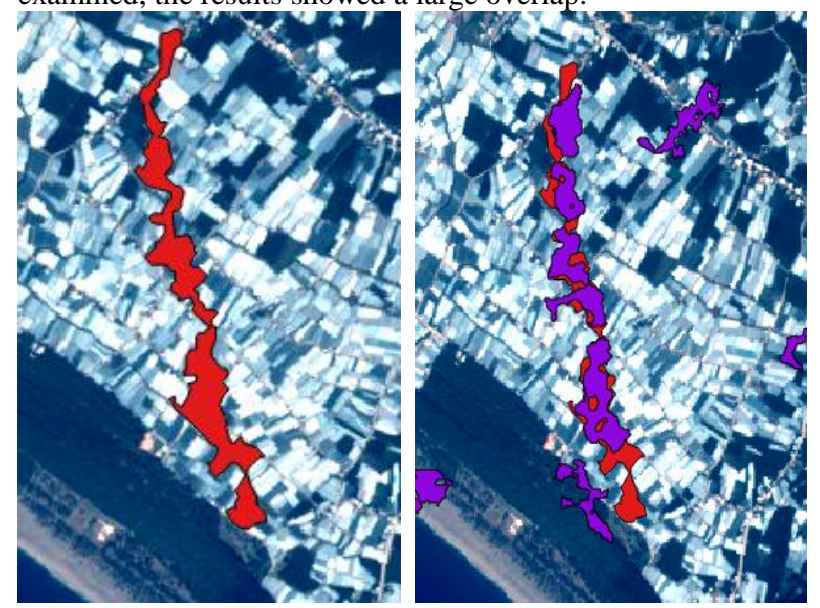

Figure 9. Detected damages(red) from S2 (left), damages(purple) from SAR when using threshold value '11' (right)

There are also areas where the result from multispectral image does not intersect with the result from SAR(Fig 9). These areas might be flooded areas which cannot be identified with multispectral image, either artefact which should be confirmed by another source of datasets. The detected damages from SAR is shown in Fig 10. in case the Eq(1) has been used.
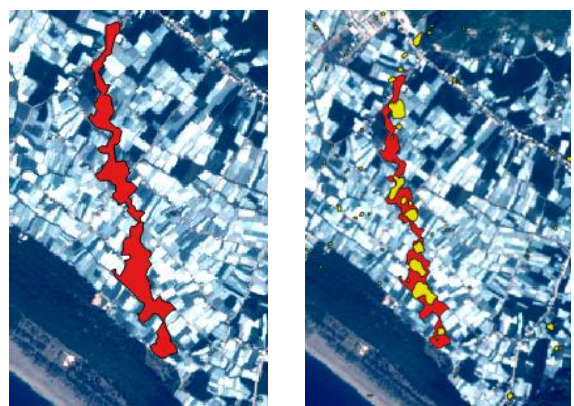

Figure 10. Detected damages(red) from S2 (left), damages(purple) from SAR when using threshold value '11' (right) 


\section{CONCLUSIONS}

In this study, the potential of SAR image was investigated for assessment of damages caused by the hurricane in the field of greenhouses. The results show that SAR images are useful to identify the areas where the hurricane touched the fields. The multispecrral image was also used to identify the areas which were effected by the hurricane. The results from SAR and multispectral image both correlate, so SAR image can be an alternative for detection of hurricane damages with its advantage for their capability to operate in all weather conditions.

\section{REFERENCES}

Aosier, B., Kaneko, M., Takada, M. (2007): Evaluation of the forest damage by typhoon using remote sensing technique. In: IEEE International Geoscience and Remote Sensing Symposium (IGARSS), pp. 3022-3026.

Ayala-Silva, T., Twumasi, Y. A., 2004. Hurricane Georges and vegetation change in Puerto Rico using AVHRR satellite data. International Journal of Remote Sensing, 25(9), pp. 1629-1640.

Bruniquel, J., Lopes, A., 1997. Multi-variate optimal speckle reduction in SAR imagery. International journal of remote sensing, 18(3), pp. 603-627.

Chehata, N., Orny, C., Boukir, S., Guyon, D., Wigneron, J. P., 2014. Object-based change detection in wind storm-damaged forest using high-resolution multispectral images. International journal of remote sensing, 35(13), pp. 4758-4777.

Chung, H. W., Liu, C. C., Cheng, I. F., Lee, Y. R., Shieh, M. C., 2015. Rapid Response to a Typhoon-Induced Flood with a SAR-Derived Map of Inundated Areas: Case Study and Validation. Remote Sensing, 7(9), pp. 11954-11973.

Čotar, K., Oštir, K., Kokalj, Ž., 2016. Radar Satellite Imagery and Automatic Detection of Water Bodies. Geodetski glasnik, 50(47), pp. 5-15.

Dobson, M. C., \& Ulaby, F. T. (1986). Active microwave soil moisture research. IEEE Transactions on Geoscience and Remote Sensing, (1), pp. 23-36.

Emekli, N. Y., Büyüktaş, D., Büyüktaş, K., 2008. Antalya Yöresinde Seraciliğin Mevcut Durumu ve Yapisal Sorunlari. Batı Akdeniz Tarımsal Araştırma Enstitüsü Derim Dergisi, 25(1), pp. 26-39.

Ermert, J., Dees, M., Koch, B., 2012. Mapping of forest damages caused by a tornado 2012 in Gera, Germany using TERRASAR-X change detection.

Eriksson, L. E., Fransson, J. E., Soja, M. J., \& Santoro, M., 2012. Backscatter signatures of wind-thrown forest in satellite SAR images. In: IEEE International Geoscience and Remote Sensing Symposium (IGARSS), pp. 6435-6438.

ESA, 2013. Sentinel-1 User Handbook. https://Sentinel.esa.int/documents/247904/685163/Sentinel-

1_User_Handbook (26 January 2018).
ESA, 2015. Sentinel-2 User Handbook. https://earth.esa.int/documents/247904/685211/Sentinel2_User_Handbook (26 January 2018).

Fransson, J. E., Walter, F., Blennow, K., Gustavsson, A., \& Ulander, L. M., 2002. Detection of storm-damaged forested areas using airborne CARABAS-II VHF SAR image data. IEEE transactions on geoscience and remote sensing, 40(10), pp. 2170-2175.

Gokaraju, B., Turlapaty, A. C., Doss, D. A., King, R. L., Younan, N. H. (2015): Change detection analysis of tornado disaster using conditional copulas and Data Fusion for costeffective disaster management. In: IEEE Applied Imagery Pattern Recognition Workshop (AIPR), pp. 1-8.

Hurriyet Gazetesi, 2017. Antalya'yı hortum vurdu: Çok sayıda yaralı var. Retrieved from http://www.hurriyet.com.tr/antalyayihortum-vurdu-cok-sayida-yarali-var-40644048 (25 January 2018).

Lee, J. S., 1983. A simple speckle smoothing algorithm for synthetic aperture radar images. IEEE Transactions on Systems, Man, and Cybernetics, (1), pp. 85-89.

MacQueen, J., 1967. Some methods for classification and analysis of multivariate observations. In: Proceedings of the fifth Berkeley symposium on mathematical statistics and probability, Vol. 1, No. 14, pp. 281-297.

MGM, 2018. Resmi Istatistikler. https://www.mgm.gov.tr/veridegerlendirme/il-ve-ilceleristatistik.asp $x$ ? $=A$ (26 January 2018).

Richards, J. A., Woodgate, P. W., Skidmore, A. K., 1987. An explanation of enhanced radar backscattering from flooded forests. International Journal of Remote Sensing, 8(7), pp. 1093-1100.

Sozcu Gazetesi, 2017. Hortum, Antalya'nın batısını yıktı geçti. Retrieved from http://www.sozcu.com.tr/2017/gundem/hortumantalyanin-batisini-yikti-gecti-2089584/ (25 January 2018).

Veci, L., 2015. SENTINNEL-1 Toolbox; SAR Basics Tutorial (1st Ed.). Array Systems Computing Inc. http://Sentinel1.s3.amazonaws.com/docs/S1TBX\%20SAR\%20 BBasic\%20Tutorial.pdf.

Wang, W., Qu, J. J., Hao, X., Liu, Y., Stanturf, J. A., 2010. Post-hurricane forest damage assessment using satellite remote sensing. Agricultural and Forest Meteorology, 150(1), pp. 122132 . 